\title{
Interactive comment on "Stable isotope investigation of groundwater recharge in the Carpathian Mountains, East-Central Europe" by Carmen-Andreea Bădăluţă et al.
}

\section{Anonymous Referee \#1}

Received and published: 15 February 2018

Unfortunately, I cannot recommend that this paper be published in its present form. The paper's title and introduction suggest that it is a recharge study; however, that is probably the least discussed of the material in the paper.

The only text that pertains to recharge is at the end of section 5.2 (page 11, lines 1123) where the main conclusions appear to be that there are few discernible patterns in the stable isotopes and this implies that the groundwater is recharged locally and may be around six months old. The first point is self-evident - recharge is always a local process, what the authors may mean is that there has been little mixing in the aquifers subsequent to recharge (although there is little data presented to test that).

Printer-friendly version

Discussion paper 
The assumptions behind the approximate residence time are also not justified and it is speculative.

The text in this section (page 11, lines 19-23) are also contradictory. To estimate the residence times or to understand the sources of water using geochemistry, there needs to be little or no mixing in the aquifers. The statement that there is "slow underground flow on the same direction of the aquifer" seems to imply that local recharge is mixed with laterally-flowing groundwater, which would not allow the geochemistry to be used in this way.

There is also insufficient detail on the hydrogeology. Specifically,

- the flow systems are not defined

- there is no indication of where the recharge areas are (Fig. 1 show many of the wells to be located in valleys, are these really in discharge areas?)

- there is no indication of wells depths, water table levels etc. If one wishes to sample recharge in wells, they need to be screened at the water table.

- the only mention of methodology relating to the groundwater is actually "The spatial variability of stable isotopes in groundwater was spatially mapped using the ordinary kriging method (Nas and Berktay, 2010)."

- 157 groundwater samples are mentioned in the abstract, but Table 2 list only 21 (and a similar number are on Fig. 3). If you are going to claim a large data set you need to present it and use it.

The paper is mainly concerned with using stable isotopes to understand moisture sources. This is not really my field of expertise although I can follow the logic of the discussion. The authors would be better to cast the paper in that way with perhaps a sentence or two at the end stating that this is important information for understanding recharge or residence times in rivers etc. 
The paper is also very specific and there are no indications of how it relates to previous work on this topic in general or the region (there are papers by Bojar et al, 2017 and Bottyan et al., 2017 that look to cover similar topics). The conclusions also do not convey any general importance and it is not clear what a reader working on these topics elsewhere would get from the paper.

At the very least, the authors need to rewrite the paper so that the title and introduction more clearly reflect the contents. Even then, the paper appears to have limited scope and may be more suited to a regional journal.

Interactive comment on Hydrol. Earth Syst. Sci. Discuss., https://doi.org/10.5194/hess-2018-6, 2018. 